\title{
Impact of Young Children's Smartphone Use and the Mediating Effects of Self-control on School Readiness
}

\author{
Yoonju Cho \\ Department of Child Studies, Chongshin University, Seoul, Korea \\ 스마트폰 이용이 유아의 학교준비도에 미치는 영향 : \\ 자기통제의 매개효과 \\ 조윤주 \\ 총신대학교 아동학과
}

Objective: This study was conducted to investigate the mediating effects of self-control in the relationship between preschooler's smartphone use and school readiness.

Methods: Data from the 7 th wave of the Panel Study on Korean Children $(N=1,078)$. Mediating effect was analyzed using Structural Equation Modeling with Bootstrapping method utilizing SPSS 21.0 and AMOS 20.0.

Results: Results showed that increased smartphone use has affected school readiness concerning social and emotional development, communication, approach to learning and cognitive development and general knowledge through self-control.

Conclusion: This indicates that while smartphone use itself does not directly affect school readiness, it seems to impede developing self-control; consequently, as self-control weakens, certain developmental domains for readiness to school may be hindered. This confirms that self-control plays an important mediating role between smartphone use and school readiness. Theoretical and practical implications, as well as limitations, are discussed.

Keywords: smartphone use, self-control, school readiness, mediating effects, bootstrapping method$$
\text { 서론 }
$$

스마트폰은 전 세계적으로 사용이 급격하게 증가하고 있으 며, 사용연령 또한 점차 낮아지고 있다(Statista, 2017). 일상생 활의 대부분을 성인과 함께 보내는 유아기의 특성상, 유아의 스마트폰 이용이 성인의 스마트폰 이용과 병행적으로 증가함 에 따라(National Information Society Agency, 2014), 스마트폰 에 몰두하는 유아의 모습은 일상생활 주변에서 흔히 발견되 고 있는 실정이다. 유아기에 스마트폰을 이용하는 것이 미디

Corresponding Author: Yoonju Cho, Department of Child Studies, Chongshin University, 143, Sadang-ro, Dongjak-gu, Seoul, Korea E-mail: yjcho4@korea.ac.kr
\end{abstract}

어 기기에 익숙하게 하고 교육적 효과가 있다는 보고(Couse \& Chen, 2010)가 있는 반면, 스마트폰 증후군을 비롯한 발달적 위험성에 대한 사회적 우려 역시 커지고 있다. 실제로, 스마트 폰 이용은 유아의 주의 및 집중력 향상에 방해가 되고, 부적응 적 행동을 이끌며(Chonchaiya \& Pruksananoda, 2008), 공격성 및 행동문제에 영향을 미침으로써 이후 발달시기까지 반사회 적인 행동문제를 이끄는 요인이 되는 것으로 나타났다(Hyde, O'Callaghan, Bor, Williams, \& Najman, 2012). 이처럼 스마트폰 이용에 따른 부정적인 결과들이 보고되면서(Lee, Do, \& Oh,

(c)The Korean Association of Child Studies

This is an Open Access article distributed under the terms of the Creative Commons Attribution Non-Commercial License (http:// creativecommons.org/licenses/by-nc/4.0) which permits unrestricted noncommercial use, distribution, and reproduction in any medium, provided the original work is properly cited. 
2013; Ostrov, Gentile, \& Crick, 2006) 유아의 스마트폰 이용에 대한 올바른 인식과 개입에 대한 요구가 커지고 있다. 더욱이, 학령 전 유아기가 학교생활로 이행을 위한 발달적 준비가 이 루어지는 시기인 만큼, 스마트폰 이용의 직·간접적 효과에 대 한 실증적인 검증이 이루어질 필요가 있다.

학령 전 유아는 초등교육으로 전환을 앞두고 새로운 사회 적 체계에 대한 적응 및 수행을 위한 발달적 준비가 필요하다. 학령기로 전환을 앞둔 유아에게 요구되는 총체적인 발달적 역 량은 학교준비도로 개념화할 수 있다. 학교준비도는 유아의 학 교환경 적응 및 학업태도와 수행을 예측하는 동시에, 현 상태 에서 유아의 발달적 양상이 적절한 지를 반영해 준다. 이러한 학교준비도에 대한 발달적 관점은 최근 수십 년 동안 커다란 전환을 이루어왔다. 종전에는 학교준비도가 학습준비를 위해 서 필수적인 학습 이해력 및 과제 수행과 같은 학습적인 요인 들에 초점을 둔 개별적인 성숙 수준으로 이해되었지만(Snow, Burns, \& Griffin, 1998), 최근에는 유아와 환경 간의 양방향성 에 초점을 두는 방향으로 관점이 변화되었다(Murph \& Burns, 2002). 이러한 관점에서 학교준비도는 유아 자신과 유아의 발 달을 최대로 이끄는 데 필요한 다양한 환경적, 문화적 경험들 간의 상호작용을 통한 결과적 산물로 이해된다. 즉, 학교준비 도는 학습능력 및 학업수행뿐 아니라, 학교생활 전반에 걸친 사회적 상호작용의 질적인 변화와 발달적 영역을 포괄한다.

구체적으로, 학교준비도를 구성하는 영역들로는 사회정서 발달, 의사소통, 학습에 대한 태도, 그리고 인지발달 및 일반적 지식이 있다. 사회정서발달 영역은 유아의 지속적인 주의, 정 서적 조절, 지시 따르기, 사회적 관계성과 사회적 인지를 반영 하는 것으로(McCabe \& Meller, 2004) 유아가 사회적 관계에서 어떻게 상호작용하며 행동을 조정할 수 있는 지를 나타낸다. 의사소통은 유아가 언어적으로 표현하고 이해하는 것을 통해 타인과 원활하게 소통할 수 있는 지를 나타내며, 학습에 대한 태도는 과제 지속성, 주의력, 창의성, 주도성, 호기심과 문제 해결력을 반영하는 것으로 과제수행을 위해서 요구되는 전반 적인 수행능력과 자질을 나타낸다(West, Denton \& GerminoHausken, 2000). 인지발달 및 일반적 지식은 논리적 측정이 나 수리적 개념의 이해를 포함하는 것으로 지식의 구성 및 학 습 수행에서 요구되는 기본적인 사고능력을 나타낸다(Raver, 2004). 이와 같이 학교준비도는 유아가 학교환경에 적응하고 그에 따른 발달적 준비를 갖추는 데 필요한 총체적인 방식이 된다. 그러므로, 학교준비도는 유아의 발달과 학습, 그리고 확 장된 사회적 체계로의 이행과 상호작용에 필요한 발달적 영역 을 반영하고, 사회적 적응 및 수행을 예측하며, 이후 시기의 발
달적 결과에 영향을 미친다는 점에서 그 중요성이 크다.

유아의 발달 영역에 영향을 미치는 사회적 요소로서 급격하 게 부상하는 것으로 스마트폰을 들 수 있다. 일상생활 장면에 서 스마트폰에 대한 노출과 접촉이 증대되고 있는 가운데, 유 아의 스마트폰 이용이 발달적 이행의 준비에 방해가 된다는 것 을 알 수 있다. 최근 연구들은 스마트폰 이용이 유아의 학습태 도 및 다차원적인 사회적 상호작용에 영향을 미친다고 보았고 (Ostrov et al., 2006), 사회정서발달에 부정적으로 작용하며(Lee et al., 2013), 언어발달과 의사소통에 결핍을 초래한다고 보고 하였다(Zimmerman, Christakis, \& Meltzoff. 2007). 스마트폰 화 면에 몰두할수록 유아의 학습태도는 좋지 않게 나타났으며, 인 지적 능력에 부정적인 영향을 미쳐 낮은 학업수행이 예측되었 다(Beland \& Murphy, 2014). 스마트폰의 과다한 이용은 유아 가 사회적 상호작용을 통해 또래관계를 형성하고 문제를 해 결하는 데에도 부정적인 영향을 미쳤다(Radesky, Schumacher, $\&$ Zuckerman, 2015). 스마트폰으로 영상매체에 많이 접촉하 는 유아는 폭력적이고 공격적인 성향이 높게 나타났고, 부정 적인 사회적 상호작용 및 행동양상을 나타내었다(Zimmerman $\&$ Christakis, 2007). 이처럼 스마트폰 이용의 증가는 사회적 상 호작용에 필요한 기술을 습득하고 훈련하는 데 필요한 경험과 활동을 감소시킴으로써(Radesky et al., 2015), 유아기에 발달해 야 할 다양한 발달영역에 부정적으로 작용한다.

유아기는 사회적 환경체계와 접촉이 많아지면서 상호작용 을 통한 자기규제 및 조절이 중요해지고 자기통제가 활발하 게 발달하는 시기이다(Lewis \& Todd, 2007). 유아기에 자기통 제는 성인에 대한 신뢰, 규칙의 내면화, 만족 지연, 분노 및 충 동 조절, 그리고 좌절에서 인내할 수 있는 내적인 방식들로 나 타나게 된다(Honing \& Lansburgh, 1991). 유아기에 활발하게 발달하는 자기통제는 아동기를 거쳐 성인기에 이르기까지 학 습태도, 학업수행, 반사회성, 또래관계 등 다양한 영역을 통 해 지속적인 영향을 미치게 된다(Thompson, Barresi, \& Moore, 1997). 특히, 학령기로 전환을 앞둔 유아가 적응적이고 성공적 인 학교생활을 하기 위해서 자신을 규제하고 조절하는 것은 매우 중요한 기제가 된다. 이러한 자기통제의 발달은 비교적 오랜 시간에 걸쳐 점차 복잡하고 심화된 차원으로 전개되어지 므로, 자기통제가 연령적 변화에 의해서 발달된다는 견해가 지속되어왔다(Cummings, Iannotti, \& Zahn-Waxler, 1989).

하지만, 최근 들어 뇌 과학 연구의 급속한 발전은 인간행동 과 두뇌 영역들 간의 관계에 대한 구체적인 증거들을 제시하 면서 유아기에 자기통제가 단순히 연령적 변화에 의하기보 다 통제를 관장하는 두뇌 영역들 간의 활발한 교류에 의한다 
는 점이 대두되었다(Tarullo, Obradovic, \& Gunnar, 2009). 이를 위해서는 두뇌의 각 영역들 간의 연결망이 구축되고 활성화 되는 과정이 중요한데, 이러한 매커니즘은 다양하고 풍부한 경험과 활동을 통해서 작동하게 된다(Tarullo et al., 2009). 유아 가 다양한 사회적 상황들에 적절하게 반응하고 균형 있게 행 동하기 위해서는 긍정적이고 수용적인 사회적 경험이 충분히 제공되어야 하며, 역동적인 상호작용이 활발하게 이루어져야 한다(Bronson, 2000).

그런데, 다양한 경험과 활동 대신에, 스마트폰 스크린에 몰 두하는 시간이 늘어나는 것은 자기통제의 형성과 발달에 필요 한 두뇌 영역들 간의 활성화에 심각한 방해가 된다. 실제로, 스 마트폰 이용과 자기통제가 밀접한 관련성이 있는 것으로 보고 되는데, 스마트폰 이용이 증가할수록 유아의 자기규제와 통 제는 낮게 나타났다(Chonchaiya \& Pruksananoda, 2008). 또한, 스마트폰을 통해 유아가 동영상 및 애니메이션에 지속적으로 노출되는 것이 만족 지연이나 사회적 상황에서 현저하게 낮 은 조절능력과 관련이 있는 것으로 나타났다(Rosbery, HirshPasek, \& Golinkoff, 2014).

유아의 자기통제는 학교생활을 준비하는 데 필요한 다양한 발달적 결과를 예측한다는 점에서 또한 중요하다(Eisenberg, Hofer, \& Vaughan, 2007). 학교준비도에 관한 연구들이 자기 통제의 중요성을 강조하고 있는 만큼(Normandeau \& Guay, 1998), 유아가 학교환경에 적응하고 사회적 상호작용을 이루 며 적절한 학업태도를 갖추는 데 자기통제는 필수적인 요소가 된다(Murphy \& Burns, 2002). 자기통제는 학습태도, 사회적 유 능성, 수행 적정성 등 적응적인 학교생활의 준비에 필요하며, 성공적인 자기통제는 학업수행, 교실환경에서의 행동 조정, 그리고 학업 및 사회적 과제에 긍정적인 영향을 미치는 것으 로 나타났다(Blair \& Razza, 2007).

자기통제가 높은 유아는 긍정적인 학습태도가 보고되었 고, 문해 및 수리의 학습 수행에서 긍정적인 결과가 나타났다 ((Blair \& Razza, 2007). 이와 달리 자기통제가 낮으면 또래 및 사회적 관계에서 친사회적 성향이 적었고, 공격적이며 사회적 지시 따르기에 부족한 것으로 보고되었다(Barkley, 1997). 자기 통제가 낮으면 자신의 감정이나 표현을 전달하기 위한 적정 한 의사소통이 이루어지기 어렵고(Bronson, 2000), 학습에 대 한 이해나 태도가 낮아 인지적 추리능력과 수리적 개념에 대 한 수행에서 낮은 점수가 보고되었다(Spira \& Fischel, 2005). 자기통제는 또래관계 및 긍정적인 관계 형성에 필수적이고 (LeCuyer \& Houck, 2006), 인지적 성취와 학습태도를 예측하 는 요인으로 알려졌다(Blair \& Razza, 2007). 이와 같이, 자기통
제는 학령 전 유아가 학교생활을 적절하게 수행하는 데 필요 한 다양한 발달영역에 필수적인 중요 요소가 된다.

지금까지 살펴본 바에 의하면, 유아의 스마트폰 이용이 사 회정서발달, 의사소통, 인지발달, 학습태도 등과 같은 다양한 발달적 영역에 부정적으로 작용하는 것으로 나타났다(Ostrov et al., 2006). 스마트폰 이용은 유아가 자기통제를 발달하는 데 필요한 다양한 활동과 경험을 제한하고, 자기규제와 조절 을 통해 통제를 발달시키는 데 부정적인 요소로 작용하였다 (Tanimuta, Okuma, \& Kyoshima, 2007). 또한, 자기통제는 또래 관계 형성, 인지적인 판단과 학습 태도, 사회적 상황에서 문제 해결 및 갈등발생을 위한 행동, 그리고 언어적인 의사표현 및 수행능력과 태도에 영향을 미치는 것으로 나타났다(Hong \& Jo, 2015; Lane, Stanton-Chapman, Jamison, \& Phillips, 2007). 이 러한 점들을 근거로 하여 본 연구에서는 유아의 스마트폰 이 용이 자기통제에 영향을 미칠 것이며, 이러한 영향이 유아의 사회정서발달, 의사소통, 인지발달 및 일반적 지식, 학습에 대 한 태도로 구성된 학교준비도에 영향을 미친다는 점을 매개효 과를 통해서 검증하고자 한다.

유아의 스마트폰 이용이 급증하고 있는 가운데, 스마트폰 이용이 다양한 발달적 준비가 요구되는 학교준비도와 유아기 에 활발하게 발달하는 자기통제에 어떠한 직·간접적인 관계 를 형성하는 지를 파악함으로써, 학령 전 유아가 학교생활로 의 발달적 이행을 준비하는 데 필요한 개입과 접근을 모색하 고자 한다. 연구문제는 다음과 같다.

\section{연구문제 1}

유아의 스마트폰 이용과 학교준비도 간의 관계에서 자기통제 의 매개효과가 있는가?

1-1. 유아의 스마트폰 이용이 자기통제를 통해서 학교준비 도에 간접효과를 나타내는가?

1-2. 유아의 스마트폰 이용이 학교준비도에 직접효과를 나 타내는가?

\section{연구방법}

\section{연구대상}

Korea Institute of Child Care and Education [KICCE])에서 주관 
Table 1

Descriptive Characteristics of the Participants

\begin{tabular}{|c|c|c|c|}
\hline & Characteristics & $N$ & $\%$ \\
\hline \multirow[t]{2}{*}{ Children's gender } & Male & 549 & 50.9 \\
\hline & Female & 529 & 49.1 \\
\hline \multirow{5}{*}{$\begin{array}{l}\text { Mother's education } \\
\text { achievement }\end{array}$} & High school and less & 319 & 29.6 \\
\hline & College graduate & 291 & 27.0 \\
\hline & University graduate & 412 & 38.2 \\
\hline & Graduate / Post graduate & 51 & 4.7 \\
\hline & Missing & 5 & .4 \\
\hline \multirow{5}{*}{$\begin{array}{l}\text { Father's education } \\
\text { achievement }\end{array}$} & High school and less & 293 & 27.1 \\
\hline & College graduate & 227 & 21.1 \\
\hline & University graduate & 442 & 41.0 \\
\hline & Graduate / Post graduate & 102 & 9.5 \\
\hline & Missing & 14 & 1.3 \\
\hline \multirow{6}{*}{$\begin{array}{l}\text { Monthly income } \\
\text { (won) }\end{array}$} & Below 2,000,000 & 28 & 2.6 \\
\hline & $2,000,000 \sim 5,000,000$ & 623 & 57.7 \\
\hline & $5,000,000 \sim 7,000,000$ & 301 & 28.1 \\
\hline & $7,000,000 \sim 10,000,000$ & 95 & 8.9 \\
\hline & Over $10,000,000$ & 29 & 2.6 \\
\hline & Missing & 2 & .1 \\
\hline \multirow[t]{3}{*}{ Residential areas } & Large city & 466 & 43.2 \\
\hline & Medium-sized city & 567 & 52.6 \\
\hline & Town & 45 & 4.2 \\
\hline
\end{tabular}

Note. $N=1,078$.

한 한국아동패널(Panel Study on Korean Children [PSKC])의 7 차년도(2016) 조사에 참여한 총 1,620 가구 중에서 본 연구의 연구문제에 포함된 모든 변인에 응답한 1,078 가구의 자료를 분석대상으로 하였다(KICCE, 2016). 대상 유아는 72개월부터 79개월까지(평균월령은 75 개월)로 6세에 해당되며, 연구대상 의 인구사회학적 특징은 표 1 에 제시하였다.

\section{연구도구}

\section{스마트폰 이용}

한국아동패널조사에서 부모면접에 의해 평정된 유아의 미디 어 사용 시간 중 휴대폰 및 스마트폰에 대한 이용 정도가 사용 되었다. 문항은 "유아가 지난 1주일 간 휴대전화 및 스마트폰 을 얼마나 이용하였습니까?”에 응답하도록 되어 있으며, 각 영 역에 대한 문항의 점수는 전혀 이용하지 않음[1점]부터 매우
자주 이용함[5점]으로 구성되어 있다. 점수가 높을수록 휴대 폰 및 스마트폰에 대한 유아의 사용량이 많은 것을 의미한다.

\section{자기통제}

자기통제는 Gresham과 Elliott (1990)의 Social skills rating system 을 Suh (2004)가 타당화한 한국판 취학전 아동용 사회적 기술 척도(K-SSRS: 교사평정용, 부모평정용)의 하위영역 중에서 자 기통제가 사용되었다. 자기통제는 유아의 부모에 의해 평정 된 7문항과 유아의 교육기관 교사가 평정한 7문항이 사용되 었으며, 부모평정에 의한 문항의 내용은 "부모의 지시에 따른 다.", "집에서 적절한 방식으로 시간을 보낸다.", "다른 사람과 게임을 할 때 규칙을 지킨다.", “집에서 알맞은 음성높이로 말 한다.” 등으로 이루어져 있다. 교사평정에 의한 문항은 “또래 에게 놀림을 당하는 경우 적절하게 대응을 한다", “또래로부 터 칭찬을 받거나 찬사에 고마움을 표현한다.", “또래와의 갈 등상황에서 자신의 감정을 조절한다.”, “또래의 압력에 대해 적절하게 대응한다.” 등으로 이루어져 있다. 각 문항의 점수는 전혀 아니다[1점], 가끔 그렇다[2점] 그리고 매우 자주 그렇다 [3점] 의 3점 척도로 구성되어 있으며, 점수가 높을수록 유아 의 자기에 대한 통제 수준이 높은 것을 나타낸다. 자기통제의 Cronbach's $\alpha$ 는 부모평정이 .79, 교사평정이 .84이었다.

\section{학교준비도}

학교준비도는 Murphey와 Burns (2002)의 Development of a comprehensive community assessment of school readiness를 번안 하여 수정한 척도가 사용되었다. 학교준비도는 부모면접에 의 해 평정되었고, 사회정서 발달(6문항), 학습에 대한 태도(8문 항), 의사소통(3문항), 인지발달 및 일반적 지식(5문항)의 4 개 하위 영역으로 구성되어있다. 각 하위영역은 4점식 Likert 척 도로 구성되어 있으며, 점수는 전혀 그렇지 않다[1점], 별로 그 렇지 않다[2점], 조금 그렇다[3점], 매우 그렇다[4점]로 이루어 져 있다. 사회정서 발달은 6 문항으로 구성되었고, 각 문항의 내용은 “또래들과 어울릴 수 있다.", "감정의 변화를 적절하게 표현한다.", "또래와의 관계에서 적절한 문제해결 기술을 사 용한다.”, "교사 등 어른들과 긍정적으로 상호작용 한다." 등으 로 이루어져 있다. 본 연구에서 사회정서발달의 Cronbach's $\alpha$ 가 . 75 이었다. 의사소통은 3 문항으로 구성되었고, 각 문항의 내용은 “욕구, 필요한 것, 생각들을 말로 표현한다.”, “간단한 지시, 요청, 정보를 이해한다", "완전한 문장으로 대화에 참여 
한다” 로 이루어져 있다. 본 연구에서 의사소통의 Cronbach's $\alpha$ 가 .85이었다. 인지발달 및 일반적 지식은 5문항으로 구성되 었고, 각 문항의 내용은 "활동을 기억하고 사건의 순서를 설명 할 수 있다." "책의 내용을 이해한다.", "자신의 생각을 표현하 기 위해 연필, 크레파스, 붓 등을 사용할 수 있다.” 등으로 이루 어져 있다. 본 연구에서 인지발달 및 일반적 지식의 Cronbach's $\alpha$ 가 .82이었다. 학습에 대한 태도는 8문항으로 구성되었고, 각 문항의 내용은 "간단한 규칙과 지시를 잘 따른다", "교사가 주 도한 집단 활동에 집중한다.”, “수업활동에 열정적으로 흥미 를 가지고 참여한다." "교실 등의 상황에서 어떤 활동을 먼저 시작한다.” 등으로 이루어져 있다. 본 연구에서 학습에 대한 태도의 Cronbach's $\alpha$ 가 .86이었다.

\section{자료분석}

자료는 SPSS 21.0과 AMOS 20.0 (IBM Co., Armonk, NY) 을 사 용하여 분석하였다. 첫째, 변인들의 일반적인 경향을 기술 통 계치와 상관분석을 통해 알아보았다. 둘째, 연구문제에 제시 한 매개효과를 분석하기 위하여 간접효과 분석에 효과적인 부 트스트랩방식을 적용하여 매개모형을 분석하였다(Bollen \& Stine, 1992). 모형을 평가하기 위한 적합도 지수로는 경험적 인 근거가 확보되어 있는 동시에 간명성을 고려하여(Browne \& Cudeck, 1993), 상대적 적합도 지수(Relative fit index)로 TLI (Tucker-Lewis index), CFI (Comparative fit index)를 사용하였고, 절대적 적합도 지수(Absolute fit index)로 RMSEA (Root mean square error of approximation)를 평가에 적용하였다.

\section{연구결과}

\section{변인들의 일반적 경향}

변인들의 일반적인 경향을 파악하기 위해서 기술통계치와 Pearson의 상관계수를 표 2에 제시하였다. 모든 측정변인들은 왜도 및 첨도 값이 정규성 분포의 가정을 총족시키는 것으로 나타나 별도의 조처를 취하지 않았다(West, Finch, \& Curran, $1995)$. 표 2에서 스마트폰 이용의 평균이 $2.30(S D=1.05)$ 로 연 구대상 유아의 스마트폰 이용은 가끔 이용하는 정도보다 높 은 수준인 것으로 나타났다. 자기통제는 부모가 평정한 평가 와 교사가 평정한 평가를 각각 측정변인으로 사용하여 다중 평정 하였고, 부모평정의 평균이 $17.68(S D=2.49)$, 교사평정 이 $16.86(S D=3.06)$ 로 부모평정에서 점수가 높게 나타났다. 학교준비도는 사회정서발달의 평균이 $21.04(S D=2.31)$, 학습 에 대한 태도의 평균이 $28.04(S D=3.24)$, 의사소통의 평균이 $10.85(S D=1.40)$, 그리고 인지발달 및 일반적 지식의 평균이 $18.21(S D=1.97)$ 로 나타났다.

변인들 간의 상관관계를 살펴보면, 유아의 스마트폰 이 용은 부모평정에 의한 자기통제와 부적 상관이 나타났고 $(r=$ $-.08, p<.01)$, 학교준비도의 하위영역인 사회정서 발달, 인지 발달 및 일반적 지식과 부적 상관 $(r=-.06, p<.05 ; r=-.06, p<$ $.05)$ 이 나타났다. 부모 평정에 의한 자기통제는 학교준비도의 하위영역인 사회정서 발달, 학습에 대한 태도, 의사소통, 인지 발달 및 일반적 지식과 정적 상관 $(r=.53, p<.01 ; r=.61, p<$ $.01 ; r=.53, p<.01 ; r=.56, p<.01)$ 이 나타났고, 교사평정에 의

Table 2

Correlations Among Variables

\begin{tabular}{|c|c|c|c|c|c|c|c|c|}
\hline & Variables & 1 & 2 & 3 & 4 & 5 & 6 & 7 \\
\hline 2. & Self control (by parent) & $-.086^{* *}$ & - & & & & & \\
\hline 3. & Self control (by teacher) & .001 & $.214^{* *}$ & - & & & & \\
\hline 4. & Social and emotional development & $-.056^{*}$ & $.529^{* *}$ & $.218^{* *}$ & - & & & \\
\hline \multirow[t]{3}{*}{7.} & Cognitive development and general knowledge & $-.064^{*}$ & $.556^{* *}$ & $.225^{* *}$ & $.563^{* *}$ & $.717^{* *}$ & $.728^{* *}$ & - \\
\hline & $\begin{array}{c}M \\
\text { (Range) }\end{array}$ & $\begin{array}{l}2.30 \\
(1-5)\end{array}$ & $\begin{array}{l}17.68 \\
(9-21)\end{array}$ & $\begin{array}{l}16.86 \\
(7-21)\end{array}$ & $\begin{array}{l}21.04 \\
(13-24)\end{array}$ & $\begin{array}{l}28.04 \\
(16-32)\end{array}$ & $\begin{array}{l}10.85 \\
(4-12)\end{array}$ & $\begin{array}{l}18.21 \\
(5-20)\end{array}$ \\
\hline & $S D$ & 1.05 & 2.49 & 3.06 & 2.31 & 3.24 & 1.40 & 1.97 \\
\hline
\end{tabular}

Note. $N=1,078$.

${ }^{*} p<.05 .{ }^{* *} p<.01$ 
Table 3

Estimates From the Mediation Model

\begin{tabular}{|c|c|c|c|c|c|c|c|}
\hline \multirow{2}{*}{ Mediation model } & \multirow{2}{*}{ a } & \multirow{2}{*}{$\mathrm{b}$} & \multirow{2}{*}{$c^{\prime}$} & \multirow{2}{*}{$S E$} & \multirow[b]{2}{*}{$p$} & \multicolumn{2}{|c|}{$95 \% \mathrm{BC}^{\mathrm{a}}$ confidence interval } \\
\hline & & & & & & Lower & Upper \\
\hline Smartphone use $\longrightarrow$ Self control $\longrightarrow$ School readiness & $-.105^{* *}$ & $.884^{* * *}$ & .035 & .057 & .004 & -.262 & -.038 \\
\hline
\end{tabular}

Note. Standardized paths are reported. $\mathrm{a}=\mathrm{X} \rightarrow \mathrm{M} . \mathrm{b}=\mathrm{M} \rightarrow \mathrm{Y}$. c' $=\mathrm{X} \rightarrow \mathrm{Y}$.

${ }^{\mathrm{a}} \mathrm{BC}=$ bias-corrected.

${ }^{* *} p<.01 .{ }^{* * *} p<.001$.

한 자기통제 역시 사회정서 발달, 학습에 대한 태도, 의사소통, 인지발달 및 일반적 지식과 정적 상관 $(r=.22, p<.01 ; r=.21, p$ $<.01 ; r=.15, p<.01 ; r=.23, p<.01)$ 이 나타났다.

\section{매개효과 검증}

연구모형인 매개모형을 검증하기 위해서 간접효과 분석에 효 과적인 부트스트랩 방식을 적용하여 분석하였다. 부트스트랩 방식을 적용한 간접효과 분석은 표본의 크기에 영향 받지 않 으면서 정상성이 위배된 경우에도 편향되지 않게 분석할 수 있다(Bollen \& Stine, 1992). 매개효과는 독립변인이 매개변인 을 통해서 종속변인에 미치는 효과가 통계적으로 유의한 것 으로 독립변인이 매개변인에 유의한 영향을 미치고 매개변인 은 다시 종속변인에 영향을 미치는 것을 나타내며(Mackinnon, 2008), 직접효과의 유무에 따라 완전매개와 부분매개로 구분 할 수 있다. 완전매개효과는 매개변인으로 인해 독립변인과 종속변인의 관계가 더 이상 유의하지 않은 것으로 독립변인의 직접효과가 사라지게 되지만, 부분 매개효과는 매개변인을 통 제한 상태에서 독립변인의 종속변인에 대한 유의한 직접효과 가 나타난다(Rucker, Preacher, Tormala, \& Petty, 2011).

부트스트랩 방식을 적용한 매개효과 분석은 $95 \%$ 신뢰수준 에서 신뢰구간의 값이 0 을 포함하지 않을 경우에 영가설이 기
Table 4

SMC of the Mediation Model

\begin{tabular}{cccc}
\hline Direct effect & Indirect effect & Total effect & SMC \\
\hline .035 & -.093 & -.058 & .776 \\
\hline
\end{tabular}

Note. SMC = Squared Multiple Correlations.

Table 5

Goodness of Fit of the Mediation Model

\begin{tabular}{ccccc}
\hline$\chi^{2}$ & $d f$ & TLI & CFI & RMSEA \\
\hline 29.768 & 11 & .994 & .980 & .040
\end{tabular}

Note. $d f=$ degrees of freedom; TLI = Tucker-Lewis Index; CFI

= comparative fit index; RMSEA = root mean square error of approximation.

각되는 것으로 검증된다. 표 3이 제시하는 바와 같이 유아의 스마트폰 이용이 학교준비도에 대해서 나타내는 간접효과의 신뢰구간이 0을 포함하고 있지 않은 것으로 나타나(-.262 $.038)$, 매개효과가 유의하였다 $(\mathrm{ab}=-.093, p=.004)$. 또한, 매 개변인을 통제한 상태에서 유아의 스마트폰 이용이 학습준비 도에 미치는 직접효과는 유의하지 않은 것으로 나타났다 $\left(c^{\prime}=\right.$ $.035, p=.225)$.

다중상관치(Squared multiple correlations)를 확인한 결과, 표 4 와 같이 스마트폰 이용과 자기통제가 학교준비도에 미치는 설명력은 약 $77 \%$ 로 나타났다. 또한, 간접효과가 유의한 가운

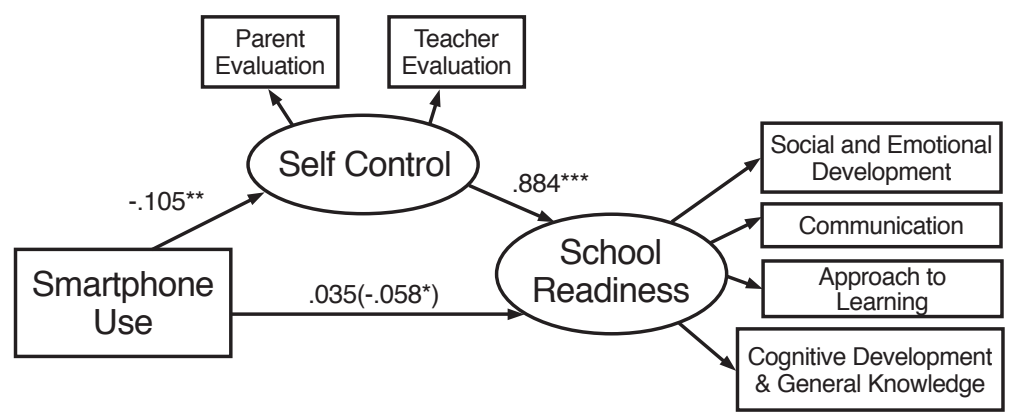

Figure 1. Mediation model. Standardized path coefficients are reported. Number inside parentheses is the standardized regression coefficient between smartphone use and school readiness, without including self-control.

${ }^{*} p<.05 .{ }^{* *} p<.01 .{ }^{* * *} p<.001$. 
데 스마트폰 이용의 직접효과가 유의하지 않아 완전 매개효과 가 나타났다. 이를 통해 자기통제가 스마트폰 이용과 학교준비 도 간의 관계에서 중요한 매개역할을 한다는 점을 알 수 있다.

연구모형인 매개모형의 적합도는 표5 에서 제시하는 바와 같이 매우 양호한 수준으로 나타났다. 적합도 지수들에 대한 평가기준은 TLI와 CFI의 경우에 .09 이상인 경우가 좋은 적합 도로 평가되고, RMSEA의 경우에는 .06 미만이면 양호한 적합 도(resonable fit)로 평가된다(Browne \& Cudeck, 1993).

\section{논의 및 결론}

본 연구는 유아의 스마트폰 이용이 학교준비도에 미치는 영향 을 자기통제의 매개변수를 고려하여 검증하였다. 연구결과, 스마트폰 이용의 증가는 자기통제를 매개로 하여 유아의 학교 준비도에 유의한 간접효과를 나타내었다. 결과를 논의하면 다 음과 같다.

첫째, 스마트폰 이용이 증가할수록 유아의 자기통제에 부 정적인 영향을 미치는 것으로 나타났다. 이러한 결과는 스마 트폰을 많이 사용할수록 유아가 사회적 상황에서 자신을 적절 하게 반응하고 조절하는 데 부정적인 영향을 미친다는 점을 말해주는 것으로, 스마트폰 이용이 자기조절 및 만족 지연에 부정적인 영향을 미친다는 결과(Chonchaiya \& Pruksananoda, 2008)를 지지해 준다. 또한, 스마트폰 이용의 증가가 유아의 집중력을 방해하고 주의를 산만하게 하며 자기규제 및 통제에 방해가 된다는 것(Rosbery et al., 2014)과 일맥상통 한다.

스마트폰의 이용이 유아의 자기통제에 부정적인 영향을 미 치는 이유로는 다음과 같이 생각해 볼 수 있다. 먼저, 유아가 스마트폰을 많이 사용할수록 스마트폰의 스크린에 몰두하며 보내는 시간이 늘어나게 되고, 이러한 경험이 많아질수록 자 발적이고 능동적인 두뇌활동을 통한 두뇌 영역 간의 활성화에 방해가 된다(Chonchaiya \& Pruksananoda, 2008). 이로 인해 자 기통제가 발달하는 데 필요한 두뇌 영역 간의 연결이 활발하 게 작동하지 못하는 것으로 볼 수 있다(Tarullo et al., 2009). 또 한, 스마트폰의 이용 시간이 증가하는 것은 다양한 환경과 접 촉하면서 상호작용을 발달시킬 경험의 기회가 줄어든다는 것 을 의미한다. 이러한 점은 스마트폰을 많이 이용할수록 자기 조절과 통제에 필요한 사회적 자극과 경험의 기회가 제한될 수 있음을 시사한다. 즉, 스마트폰 이용 시간의 증가는 환경적 자극과 경험의 감소를 초래하여 유아기 발달의 중요과제인 자 기통제 형성에 부정적인 영향을 미칠 수 있다. 마지막으로, 스
마트폰 이용이 많을수록 양육자를 통한 스마트폰 이용의 규 제가 규칙적으로 이루어지기 어렵고 맹목적인 허용이 이루어 지기 쉽다는 점이다. 유아기에 자기통제가 양육자와의 질적 인 상호작용과 반응적 양육에 의해 발달된다는 점에서(Laibel, Panfile \& Makariev, 2008), 스마트폰 사용에 대한 비규제적 양 육은 유아의 자기통제 발달에 부정적으로 작용할 수 있다.

둘째, 자기통제가 학교준비도에 영향을 미치는 것으로 나타 나, 스마트폰 이용의 증가로 인한 낮은 자기통제가 유아의 사 회정서발달, 의사소통, 인지발달 및 일반적 지식 그리고 학습 태도의 발달에 방해가 되는 것으로 나타났다. 이러한 결과는 자기통제가 사회성 및 또래관계 적응에 영향을 미친다는 결과 (Guralnick, 1992)와 맥을 같이하고, 사회적 상호작용 및 언어 적 의사소통, 또래관계에 영향을 미친다는 결과를 지지해 준다 (Hong \& Jo, 2015; LeCuyer \& Houck, 2006). 또한, 자기규제가 인지능력과 학습수행 및 학습태도에 영향을 미친다는 결과들 (Spira \& Fischel, 2005)과 일맥상통 한다.

학교준비도에 부정적인 영향을 미치는 낮은 자기통제는 다 음의 몇 가지에 의해서 기인될 수 있다. 먼저, 유아의 스마트폰 사용이 부적절한 양육의 일환으로 증가되면서 자기통제가 낮 아질 수 있다는 점이다. 스마트폰 이용에 대한 양육자의 편의 적, 비규제적 양육은 자기통제 발달에 필요한 반응적, 규제적 그리고 촉진적인 양육이 이루어지지 못한 결과로써 유아의 스 마트폰 이용을 증가시킬 수 있다. 유아의 자기통제가 규제적인 양육과 양육자와의 긴밀한 상호작용에 의해서 매우 큰 영향을 받는 만큼, 비규제적 양육으로 인한 스마트폰 이용의 증가는 낮은 자아통제를 형성하게 된다(Laibel et al., 2008). 이렇게 형 성된 낮은 자기통제는 유아가 학교생활 준비를 위해서 발달시 켜야 할 다양한 영역에 부정적으로 작용하게 된다. 또한, 낮은 자기통제는 스마트폰 이용에 대한 바람직하지 못한 모델링 효 과로 형성될 수 있다. 양육자가 스마트폰 이용에 대한 자기규 제가 부족하고, 맹목적이거나 과다하게 이용하는 것은 유아에 게 바람직하지 못한 모델링이 될 수 있다. 이러한 부정적인 모 델링은 유아의 스마트폰 이용을 증가시키고 학교생활을 준비 하는 데 필요한 자기조절과 통제에 불균형을 초래할 수 있다. 자기통제가 부정적인 환경요인에 의해서 장기적인 문제로 이 어질 수 있는 만큼(Blair \& Razza, 2007), 비규제적인 양육이나 모델링에 의해서 유아의 스마트폰 이용이 과다하게 증가하지 않도록 주의가 필요하다.

셋째, 본 연구의 매개모형에서 유아의 학교준비도에 대한 스마트폰 이용의 직접효과가 나타나지 않았다. 이러한 점은 스마트폰 이용이 학령기로의 적응적인 이행을 위해서 필요한 
발달영역에 직접적인 영향을 미치기보다 이들 영역이 기능하 는 데 필요한 자기통제를 방해함으로써 부정적인 영향을 미 친다는 점을 의미해 준다. 유아의 스마트폰 이용과 발달적 영 향을 살펴본 연구들은 주로 스마트폰 이용과 관련 변인들 간 의 직접적인 영향을 파악했던 것에 비해, 본 연구는 자기통제 의 매개역할을 고려함으로써 스마트폰 이용과 학교준비도 간 의 직·간접적인 관계를 제시해 주었다. 이를 통해서, 유아기에 활발하게 발달하는 자기통제가 학교준비도에 대한 스마트폰 이용의 부정적인 효과를 매개하는 중요한 요소가 된다는 점을 구체화하였고, 예방과 개입을 위한 시사점을 제시하였다.

넷째, 유아가 스마트폰을 이용하는 시간이 증가하는 것은 자기통제 및 학교준비도에 부정적인 영향을 미치는 것으로 나 타났다. 즉, 학령기를 앞두고 발달적 요구가 커지는 유아기에 스마트폰을 많이 이용하는 것은 유아의 자기통제 및 학교생활 준비를 위한 다양한 발달 영역에 부정적인 효과를 나타낸다. 양육자는 유아가 미디어 기기에 보다 익숙해지고 과학기술에 친숙해질 수 있도록 스마트폰의 이용을 허용하고 장려하는 경 향이 있다(Roy \& Paradis, 2015). 하지만, 이러한 허용이 스마트 폰 이용을 증가시키면서 유아의 주의가 산만해지도록 하고, 스 마트폰 사용이 제한되는 상황에서 유아를 화나게 하거나 짜증 나게 한다는 점을 간과해서는 안된다(Roy \& Paradis, 2017). 또 한, 양육자의 스마트폰 이용 시간이 유아의 스마트폰 이용시 간을 예측하는 매우 강력한 요소인 만큼(Lauricella, Wartella, \& Rideout, 2015), 스마트폰 이용에 대한 적정한 이용시간 및 제 한 범위가 체계화되어야 하겠다. 유아의 스마트폰 이용 시간에 일관된 규칙이 제공되어야 하겠으며, 스마트폰이 바람직한 양 육의 일환으로 이용될 수 있도록 조정과 감독이 이루어져야 한 다(Lee et al., 2013). 아울러, 스마트폰의 과잉 이용이 유아의 발 달에 미치는 위험성을 경고할 수 있는 가이드라인이 구축될 필 요가 있겠고, 스마트폰 과잉 이용의 위험을 예측하고 이용 습 관을 평가할 수 있는 도구 개발이 이루어져야 하겠다.

유아가 양육자 및 유아기관의 교사 등 성인과 대부분의 시 간을 보내게 된다는 점에서, 양육자는 유아가 자신에 대한 통 제를 발달시킬 수 있도록 다양한 경험과 상호작용의 기회를 충분히 제공하여야 한다. 또한, 스마트폰 이용에 대한 허용과 방임에 대한 경계가 모호하고 명확하게 제시되기 어렵다는 점 에서, 양육자는 스마트폰을 통한 미디어 방임이 자행되지 않 도록 각별한 경각심을 가져야 하겠다. 유아교육기관의 교사들 역시 스마트폰을 통해서 주의집중을 유도하거나 즉각적인 대 체물로 이용하는 것이 유아의 자기통제와 학교준비를 위한 발 달 영역에 부정적인 영향을 미치게 된다는 점을 유념해야 할
것이다. 유아가 스마트폰에 지나친 관심을 보이거나 강한 사 용 욕구를 드러낼 때, 교사는 유아의 스마트폰 사용 방식이 적 절한 지에 대한 의구심을 가지고 가정과 연계한 모니터링과 지도를 병행해야 할 것이다. 이를 위해서 유아기의 발달적 특 징을 반영한 스마트폰 이용에 대한 교육적 지침이 마련되어야 하겠으며, 과잉 이용으로 인한 발달적 위험성을 예방하고 중 재할 수 있는 프로그램이 개발되고 활성화될 수 있는 제도적 인 기반이 마련되길 바란다. 마지막으로, 유아의 스마트폰 이 용 증가로 인한 발달적 폐해가 중재될 수 있는 후속연구들이 다양한 접근을 통해서 전개되어지길 기대한다.

연구에서 제한점과 후속 연구를 위한 제언은 다음과 같다. 본 연구에서는 7차 아동패널자료를 사용하여 학령 전 유아의 스마트폰 이용이 자기통제 및 학교준비도에 미치는 매개효과 를 검증하였다. 자료분석에는 대단위 패널 자료를 이용하였고, 부트스트랩 방식을 적용하여 간접효과 분석의 한계점을 보완 하였으며, 다중측정 방식으로 측정의 객관성을 높이고자 하였 다. 그럼에도 불구하고 제한점을 언급하면 다음과 같다. 먼저, 유아의 스마트폰 이용에 대한 평정이 주 양육자에 의해 이루어 진 만큼 주관적인 요인이 가미될 수 있겠다. 또한, 자기통제 점 수에서 부모 평정이 교사 평정보다 높은 점수를 나타내었는데, 이러한 차이는 양육자와 교사가 처한 환경적 세팅이 각기 다른 만큼 각 영역에서 유아에게 기대하는 통제의 기술이나 중요도 의 차이에서 기인한 것으로 보인다(Lane et al., 2007).

본 연구에서 나타난 매개효과는 직접효과가 유의하지 않아 완전 매개효과가 나타났다. 이러한 결과는 연구모형의 매개변 인이 변인들 간의 관계에서 유일한 매개요소가 된다는 점을 의 미하지 않는다(Rucker et al., 2011). 오히려 유아의 스마트폰 이 용과 학교준비도 간의 관계는 이들 관계를 매개할 수 있는 또 다른 변인들이 탐색됨으로써 보다 잘 이해될 수 있겠다. 마지 막으로, 본 연구가 횡단적인 접근 방식으로 이루어진 만큼, 추 후 연구에서는 유아부터 청소년기까지 발달적 변화에 따른 변 인들 간의 관계를 종단적인 방식으로 검증해 보는 것도 의미가 있겠다. 향후 연구에서는 유아의 스마트폰 이용과 학교준비도 간의 중재요인들을 탐색하여 개입과 예방을 위한 가이드라인 을 구축하고 확장하는 데 기여가 되길 바란다.

\section{Conflict of Interest}

No potential conflict of interest relevant to this article was reported. 


\section{References}

\section{In English}

Barkley, R. A. (1997). ADHD and The Nature of Self-Control. New York: The Guildford Press.

Beland, L., \& Murphy, R. J. (2014). Ill Communication: Mobile Phones \& Student Performance. London: London School of Economics and Political Science.

Blair, C., \& Razza, R. P. (2007). Relating effortful control, executive function, and false belief understanding to emerging math and literacy ability in kindergarten. Child Development, 78(2), 647-663. doi:10.1111/j.1467-8624.2007.01019.x

Bollen, K. A. \& Stine, R. A. (1992). Bootstrapping goodness-of-fit measures in structural equation models. Sociological Methods and Research, 21(2), 205-229. doi:10.1177/0049124192021002004

Bronson, M. (2000). Self-Regulation in Early Childhood.: Nature and Nurture. New York: The Guildford Press.

Browne, M. W., \& Cudeck, R. (1993). Alternative ways of assessing model fit. In K. A. Bollen \& J. S. Long (Eds.). Testing structural equation models (pp. 136-162). Newbury Park. CA: Sage.

Chonchaiya, W., \& Pruksananonda, C. (2008). Television viewing associates with delayed language development. Acta Paediatrica, 97(7), 977-982. doi:10.1111/j.16512227.2008.00831.x

Couse, J., \& Chen, W. (2010). A tablet computer for young children? Exploring its viability for early childhood education. Journal of Research on Technology in Education, 43(1), 75-96. doi:10.1080/15391523.2010.10782562

Cummings, E. M., Iannotti, R. J., \& Zahn-Waxler, C. (1989). Aggression between peers in early childhood: Individual continuity and developmental change. Child Development, 60(4), 887-895. doi:10.2307/1131030

Eisenberg, N., Hofer, C., \& Vaughan, J. (2007). Effortful Control and Its Socioemotional Consequences. In J. J. Gross (Ed.), Handbook of emotion regulation (pp. 287-306). New York: Guilford Press.

Gresham, F. M., \& Elliott, S. N. (1990). Social skills rating system: Manual. Washington, DC: American Guidance Service.

Guralnick, M. J. (1992). A hierarchical model for understanding children's peer-related social competence. In S. L. Odom, S. R. McConnell, \& M. A. McEvoy (Eds.), Social competence of young children with disabilities: Issues and strategies for intervention (pp. 37-64). Baltimore, MD: Brookes.

Honig, A. S., \& Lansburgh, T. (1991). The tasks of early childhood: The development of self-control part II. Day Care and Early Education, 18(4), 21-22. doi.:10.1007/BF01617293

Hyde R, O’Callaghan, M. J., Bor, W., Williams, G. M., Najman, \& J. M. (2012). Long-term outcomes of infant behavioral dysregulation. Pediatrics. 130(5), 1243-1251. doi:10.1542/ peds.2010-3517

Laible, D., Panfile, T., \& Makariev D. (2008). The Quality and Frequency of Mother-Toddler Conflict, Links With Attachment and Temperament. Child Development. 79(2), 426-443. doi:10.1111/j.1467-8624.2007.01134.x

Lane, K. L., Stanton-Chapman, T., Jamison, K. R., \& Phillips, A. (2007). Teacher and parent expectations of preschoolers' behavior: Social skills necessary for success. Topics in Early Childhood Special Education, 27(2), 86-97. doi:10.1177/02 711214070270020401

Lauricella, A. R., Wartella, E., \& Rideout, V. J. (2015). Young children's screen time: The complex role of parent and child factors. Journal of Applied Developmental Psychology, 36, 1117. doi:10.1016/j.appdev.2014.12.001

LeCuyer, E., \& Houck, G. (2006) Maternal limit-setting in toddlerhood: Socialization strategies for the development of self-regulation. Infant Mental Health Journal, 27(4), 344370. doi:10.1002/imhj.20096

Lewis, M. D., \& Todd, R. M. (2007). The self-regulating brain: Cortical-subcortical feedback and the development of intelligent action. Cognitive Development, 22(4), 406-430. doi:10.1016/j.cogdev.2007.08.004

MacKinnon, D. P. (2008). Introduction to statistical mediation analysis. New York: Erlbaum.

McCabe, P., \& Meller, P. (2004). The relationship between language and social competence: How language impairment affects social growth. Psychology in the Schools, 41(3), 313321. doi:10.1002/pits.10161

Murphy, D., \& Burns, C. (2002). Development of a comprehensive community assessment of school readiness. Early Childhood Research \& Practice 4(2), 1-15.

Normandeau S, Guay F. (1998). Preschool behavior and first-grade school achievement: The mediational role of cognitive selfcontrol. Journal of Educational Psychology, 90(1), 111-121. doi:10.1037/0022-0663.90.1.111

Ostrov, J. M., Gentile, D. A., \& Crick, N. R. (2006). Media exposure, aggression and prosocial behavior during early childhood: A longitudinal study. Social Development, 15(4), 612-627. doi:10.1111/j.1467-9507.2006.00360.x

Radesky, L. S., Schumacher, J., \& Zuckerman, B. (2015). Mobile and interactive media use by young children: The good, the bad, and the unknown. Pediatrics, 135(1), 1-3. doi:10.1542/ peds.2014-2251

Raver, C. C. (2004). Placing emotional self-regulation in sociocultural and socioeconomic contexts. Child Development, 75(2), 346353. doi:10.1111/j.1467-8624.2004.00676.x

Roseberry, S., Hirsh-Pasek, K., \& Golinkoff, R. M. (2014). Skype me! Socially contingent interactions help toddlers learn language. Child Development, 85(3), 956-970. doi:10.1111/ 
cdev.12166

Roy, R., \& Paradis, G. (2015, March). Smartphone use in the daily interactions between parents and young children. Poster presented at Society for Research in Child Development, Philadelphia, PA.

Rucker, D. D., Preacher, K. J., Tormala, Z. L., \& Petty, R. E. (2011). Mediation analysis in social psychology: Current practices and new recommendations. Social and Personality Psychology Compass, 5(6), 359-371. doi:10.1111/j.17519004.2011.00355.x

Snow, C. E., Burns, M. S., \& Griffin, P. (1998). Preventing reading difficulties in young children. Washington, DC: National Academy Press.

Spira, E. G., \& Fischel, J. E. (2005). The impact of preschool attention, hyperactivity, and impulsivity on social and academic development: A review. Journal of Child Psychology and Psychiatry, 46(7), 755-773. doi:10.1111/j.14697610.2005.01466.x

Statista (2017). Dossier on Smartphones: Smartphones-statistics \& Facts. Retrieved from https://www.statista.com/statistics/

Tanimura, M., Okuma, K., \& Kyoshima, K. (2007). Television viewing, reduced parental utterance, and delayed speech development in infants and young children. Archives of Pediatrics \& Adolescent Medicine, 161(6), 618-619. doi:10.1001/ archpedi.161.6.618-b

Tarullo, A. R., Obradovic, J. \& Gunnar, M. R. (2009). Self-control and the developing brain. Zero to Three, 29(3), 31-37.

Thompson, C., Barresi, J., \& Moore, C. (1997) The development of future-oriented prudence and altruism in Preschoolers. Cognitive Development, 12(2), 199-212. doi:10.1016/S08852014(97)90013-7

West, J., Denton, K., \& Germino-Hausken, E. (2000). America's Kindergartners: Early Childhood Longitudinal StudyKindergarten Class of 1998-99. Retrieved from ERIC database (ED438089).

West, S. G., Finch, J. F., \& Curran, P. J. (1995). Structural equation models with nonnormal variables: Problems and remedies. In R. H. Hoyle (Ed.), Structural equation modeling: Concepts, issues, and applications (pp. 56-75). Thousand Oaks, CA: Sage Publications, Inc.

Zimmerman, F. J, Christakis, D A. (2007). Associations between content types of early media exposure and subsequent attention problems. Pediatrics, 120(5), 986-992. doi:10.1542/ peds.2006-3322

Zimmerman, F. J., Christakis, D. A., \& Meltzoff, A. N. (2007). Associations between media viewing and language development in children under age 2 years. Journal of Pediatrics, 151(4), 364-368. doi:10.1016/j.jpeds.2007.04.071

\section{In Korean}

Hong, K.-P., \& Jo, J.-O. (2015). Impact of proneness to media and internet addiction on problem behaviors in preschoolers. Korean Journal of Early Childhood Education, 35(4), 469491. doi:10.18023/kjece.2015.35.4.021

Korea Institute of Child Care and Education. (2016). Panel Study on Korean Children 7th survey [Data file and code book]. Retrieved from http://panel.kicce.re.kr/.

Korea Institute of Child Care and Education. (2017). Instrument profile for Panel Study of Korean Children 7th survey. Retrieved from http://panel.kicce.re.kr/.

Korea Institute of Child Care and Education. (2014). Issue Paper (Report No. 2014-14). Retrieved from KICCE website: http://www.kicce.re.kr/kor/index.jsp

Lee, J. R., Do, N. H., Oh, Y. J. (2013). Current status and protective measures of young children's exposure to media devices (Report No. 2013-15) Seoul: Korea Institute of Child care and Education.

National Information Society Agency. (2014). Digital media addiction and its developmental correlates in early childhood. Retrieved from http://www.nia.or.kr/site/nia_kor

Suh, M. O. (2004). A validation of the Korean version of the Social Skill Rating System for preschool level (K-SSRS: Teacher and Parent Forms). Korean Journal of Early Childhood Education, 24(2), 223-242.

\section{ORCID}

Yoonju Cho https://orcid.org/0000-0002-4346-6965

Received April 23, 2018

Revision received July 23, 2018

Accepted July 30, 2018 